\title{
Teaching pattern diversification for optics course: motivate interest, open minds and apply flexibly
}

Yunxin Wang, Dayong Wang, Lu Rong, Jie Zhao

Yunxin Wang, Dayong Wang, Lu Rong, Jie Zhao, "Teaching pattern diversification for optics course: motivate interest, open minds and apply flexibly," Proc. SPIE 9793, Education and Training in Optics and Photonics: ETOP 2015, 97930W (8 October 2015); doi: 10.1117/12.2223091

Event: Education and Training in Optics and Photonics: ETOP 2015, 2015, Bordeaux, France 


\title{
Teaching pattern diversification for optics course: motivate interest, open minds and apply flexibly
}

\author{
Wang Yunxin *a,b ${ }^{*}$ Wang Dayong*a,b, Rong Lu ${ }^{\text {a,b }}$, Zhao Jie ${ }^{\mathrm{c}}$, \\ ${ }^{a}$ College of Applied Sciences, Beijing University of Technology; Beijing 100124, China; ${ }^{\mathrm{b}}$ Beijing \\ Engineering Research Center of Precision Measurement \& Control Technology and Instruments, \\ Beijing 100124, China; ${ }^{c}$ The Pilot College Beijing University of Technology Beijing 101101, China
}

\begin{abstract}
Optics is one of the most important basic courses for college students majoring in Applied Physics in university, which can supply the essential theoretical foundation for the subsequent courses such as Information Optics and Electrodynamics etc.. So Optics course plays a supporting effect in the knowledge frame of the college students. Optics course has its own feature, for one thing, many optical contents cannot be understood directly and easily, for another the optical phenomenon or experiments are interesting and can be displayed intuitively. Considering the above feature, the diversiform teaching patterns are developed to improve the teaching effect. To motivate their interest, students have the chance to visit optical laboratory for both teaching demonstration and science research, and voluntary demonstration of teaching apparatus in class are another approach. Furthermore, digital simulation and experimental design according to the classical knowledge are introduced to the optics course, so students can comprehend and verify the optical principle. Students are encouraged to propose new ideas, and these ideas can be achieved with the help of teachers and the funds support from our university. Besides, some talent students will be invited to join a research group composing by graduate students and teachers. In this group, the students have the chance to touch frontier topics in optics. The diversification of teaching patterns can supply a developing space with the rising gradient for students, which can inspire the interest, open their minds and make them apply flexibly by the participatory and inquiry.
\end{abstract}

Keywords: optical course, teaching pattern, diversification

\section{INTRODUCTION}

Optics is one of the oldest basic disciplines in Physics, meanwhile, is the most active research field. In another word, both the technicality and practicability are contained by optics [1]. Optics focuses on the nature of light, the produce and propagation of light, the interaction between the light and matter, and the applications in the science research and engineering technology. The science and applications of light play an important role in the industrial inspection, optical communications, environment, medical health and cosmetology etc., which has created revolutionary technologies that directly improve the quality of life all over the world [2-5]. The International Year of Light is a remarkable opportunity to coordinate the international activities and promote new initiatives to the tremendous potential of light technologies. Apparently, the continuable developments of optical research and applications mostly depend on the young excellent students to some extent in the future. Therefore, the professional education has attracted more and more attention in every country.

In China, there are two kinds of the first-level disciplines closely related to optical filed: Physics and Optical Engineering, and they are composed of several second-level disciplines including Applied Physics, Optical Information Science \& Tech., Measurement Tech. \& Instrumentation, and Information Engineering etc.. In most of the department of physics or applied physics such as Beijing University, Nankai University, Fudan University and Beijing University of Technology, the pure optics science education is addressed. More practical optical technique education is focused on by College of Optical Engineering such as Nanjing University of Technology, Changchun University of Technology etc.. Meanwhile, some departments, for example, Tsinghua University, Tianjin University usually pay attentions to both science and engineering education. The emphasis of optics course is different for the diverse disciplines accordingly.

For the students majoring in the Applied Physics in our college, the optics course is the first professional course for the students, and palys a basic function for the subsequent courses such as Information Optics and Electrodynamics etc.. According to the knowledge structure of students, physical optics is more important than geometrical optics. Firstly, the

Education and Training in Optics and Photonics: ETOP 2015, edited by Eric Cormier, Laurent Sarger Proc. of SPIE Vol. 9793, 97930W · @ 2015 SPIE, IEEE, OSA, ICO · doi: 10.1117/12.2223091 
learning outcomes and objective of optics course are introduced. Then the diversity teaching models are discussed, all of which can help to motivate their interest to optics, open minds and make them apply the knowledge flexible.

\section{DIVERSIFORM TEACHING PATTERN}

The optics course is 4.0 credit including 64 class hours, and the learning outcomes and objective of optics course is:

1) Master the basic principle of inference, diffraction and polarization.

- Be able to comprehend the wave nature of light, and know some applications based on interference, diffraction and polarization in optical measurements.

2) Be familiar with the basic concepts of geometrical optics, and imaging in the paraxial situation, and the imaging principle of the visual instruments.

- Analyze the imaging results such as the image location, size of the object.

3) Know the scatter and the quantum nature of light.

4) Improve the analytic ability of students in the demonstration experiments and class education.

- Apprehend the scientific research methods: observation-hypothesis-inference-experiments-verification. Culture students the dialectical materialism views of the world.

Next, the diversity teaching models of optics course are discussed in detail. To motivate the interest of students, we have provided them the chance to visit the optical laboratories including teaching demonstration and science research. Digital simulation and experimental design based on the optical knowledge are introduced to the optics course. Students are encouraged to propose new ideas, and these ideas can be achieved with the help of teachers and university. Besides, some talent students will be invited to join a research group composing by graduate students and teachers.

\subsection{Motivate study interest to Optics}

Interest is the motive power of education. While, how to keep the interest of the students? We try to supply many opportunities in different aspects. Firstly, practical training for students is added before the study of professional course in recent years. Students have the chance to visit some company engaged in optical instruments. They are allowed to look around the production line of several companies such as Beijing Beifen-Ruili Analytical Instrument (Group) Co. Ltd. This is helpful for the students to know the applications of the optical technique in the larger sense. During the process of invitation, students usually ask many questions related with technique, and some issues are exactly the problem that the faculty of company is trying to solve. Actually, many problems will be settled with the development of scientific technique, which make students investigate that there are many things to do and increase the motivation of study.

The demonstration hall has exhibited many principle prototypes or interesting optical experimental phenomenons in our college, which includes michelson interferometer, resolution of imaging system, the spectrum of grating etc.. These optical phenomenons can raise the interests of students, and help students to deeply comprehend the optical theories introduced in class. Furthermore, there are three correlative research laboratories composed by information optics laboratory, micro-nano optics laboratory and optical fiber communication laboratory in our university. Students are invited to visit these laboratories. During the invitation, students can fully aware the status of the optics researches, and they can know or operate the common optical components.

Besides, the basic optical theory is generally explained as the teaching content in class. The related applications or instruments, especially the research frontiers in optics, are introduced in class, and these usually attract the attention of students and broaden their view. Of course, this kind of class demands that the teachers should have experience of research about optics and be able to keep up with the development of optical technology. All of these work try to make students investigate the actual applications and developments of optics technology, and know the frontier of scientific research.

\subsection{Digital simulation and experimental design by students}

Supposing that the incident light is a simple harmonic wave, most of the interference and diffraction theories can be simulated by software such as Matlab or Excel. The simulated results can help them comprehend the meaning of some 
difficult theories. For example, the nature of Thomas Young dual-slit interference experiment is the interference of two spherical lights. In the 3D space, the interference patterns of two spherical lights $\mathrm{S}_{1}, \mathrm{~S}_{2}$ are different for the screen $m$ in different directions. Some students cannot understand this. According to the optical path difference $\Delta=r_{2}-r_{1}$, the interference pattern is a cluster of two-sheeted hyperboloid of revolution with the focus points $S_{1}, S_{2}$ [6], and the simulated results are shown in Fig. 1. The 3D optical field for the constructiue interference is described in Fig. 1 (a). Figure 1(b-d) are the interference patterns respectively when detecting on the planes parallel to $y-z$ plane, $x-y$ plane and a tilted plane. With the help of the simulated stereo image, students can observe the interference pattern intuitively.

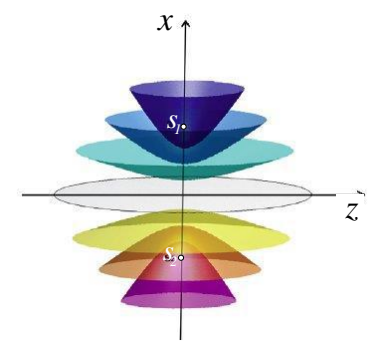

(a)

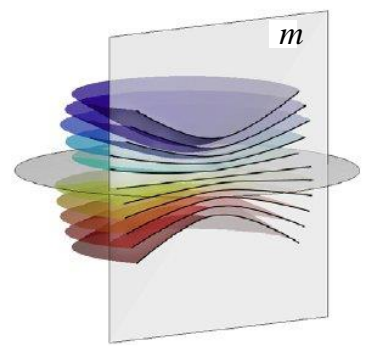

(c)

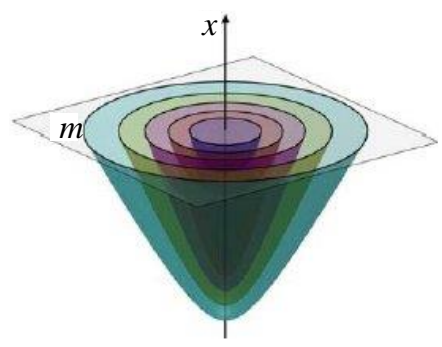

(b)

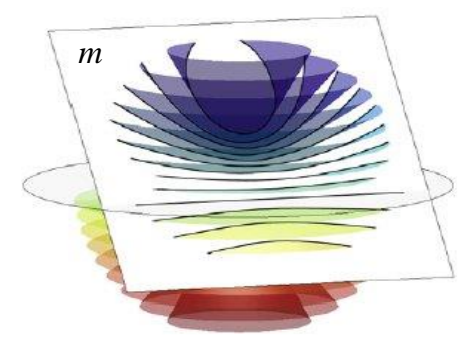

(d)

Figure 1. Simulation results for the interference of two spherical lights. (a) 3D optical field for the constructiue interference. (b) Interference pattern when detecting on a plane parallel to $y$-z plane. (c) Interference pattern on a plane parallel to $x-y$ plane. (d) Interference pattern when detecting by a tilted plane.

Besides, some demonstrations are proposed and designed by students. For instance, a demonstration apparatus for the measurement of Brewster angle is produced this year. In the demonstration apparatus, a laser pen is used as light source, an optical glass is utilized as the reflection interface, and a dial scale carved by laser is applied to confirm the angle directly. Not only the Brewster law can be demonstrated by the apparatus, but also the Fresnel formula can be proved quantitatively in the combination with polarizing beam splitter (PBS) and optical power meter. The practical teaching demonstration indicates that the apparatus can effectively assist students understanding the relationship between the incident light power and reflected light power in the interface of isotropic mediums, which can motivate the studying enthusiasm of students with a good teaching effect. Though the principle and the structure of the demonstration apparatus is simple, the design process can ensure that students can understand the theory clearly and further improve their practical ability.

\subsection{Help students achieve their ideas}

During the study of the optics course, students may have some interesting ideas in combination of practical applications. For one thing, students need the guidance of teachers; for another, they don't have enough money to achieve their minds. Considering this case, our university and teachers can help them if their ideas are of significance. Students can apply for the Plan of Talent Students or Starfire Fund from university. There will be some money to buy the necessary elements, and teachers can discuss with students and give a feasible scheme. Meanwhile, students try to achieve the targets under the guidance of teachers. Since the principles of the microscope and telescope are introduced in the class, many students would like to design the structure of some imaging systems. For example, one of our students is interested in the optimization of car light. He used the software Tracepro to simulate and calculate the parameters of LED light, and then made the light. The performance is improved by optimization of LED. Once the students have this experience, they will 
be brave to propose their ideas, and know the basic steps to realize their target. All of these are helpful for their subsequent work or study.

\subsection{Invite talent students to join special research groups}

The capability of students is different, and some talent students have free time and would like to do some special research. Especially, the students supported by the funds of university have the stronger motivation to enter a laboratory earlier. Meanwhile, teachers usually have some national or city level funds, and would like to invite talent students to join their research groups. In our group, we have a scientific seminar per week, and students are also invited to join it. These students have the chance to discuss with the graduate students and teachers. During the discussion, they can learn how to search the related references and how to give the feasible plan. After the decision of the research plan, they have the opportunity to do experiments in the laboratory under the guidance of teachers. They can revise the experimental scheme continually. Some students may achieve their targets, but not all of students can be satisfied with the results. However, the process is more important than the result.

It is useful for students to join the research group. For one thing, students can combine the theory with experiments, and apply the basic knowledge to settle the practical problem and optimize the scheme. In the laboratory, students can be familiar with many optical instruments and learn to operate them. All of these can improve their analytical and manipulative ability. For another, undergraduates are also a good supplement to our group. These students are young and active. Though they lack of some experience, they can also supply some new and simple methods to solve the problems. Furthermore, students can improve their cooperation ability during the discussion with the graduate students and teachers.

\section{CONCLUSIONS}

Optics is one of the most important courses for college students majoring in Applied Physics, and plays a supporting effect in the knowledge frame. The diversiform teaching patterns are developed to improve the professional capability of students. To motivate their interest, students are invited to visit teaching demonstration and science research except the voluntary demonstration of teaching apparatus in class. Digital simulation and experimental design are emphasized according to the classical knowledge, which accelerate students to comprehend the optical principles. Students are encouraged to propose their ideas, and these ideas can be achieved with the help of teachers and the funds support from university. Furthermore, some talent students have the chance to join a research groups and touch frontier topics in optics. The diversification of teaching patterns can inspire the interest, open their mind and make them apply flexibly by the participatory and inquiry.

\section{ACKNOWLEDGEMENTS}

This work is financially supported by the National Natural Science Foundation of China (No. 61205010, 61307010, 61475011, 51477028, and 61372061), the Research Fund for the Doctoral Program of Higher Education of China (No. 20121103120003), Science and Technology Project of Beijing Municipal Commission of Education (No. KM201310005031), the Importation and Development of High-Caliber Talents Project of Beijing Municipal Institutions (CIT\&TCD201504020), and Young Talent Project of Beijing University of Technology.

\section{REFERENCES}

[1] Eugene, H., [Optics (4th Edition)], Addison Wesley Publishers, New York \& Boston,1-9 (2001).

[2] Boucouvalas, A. C., "Challenges in Optical Wireless Communications, Optics and Photonics News," 16(9), 3639 (2005).

[3] Wang, Y. X., Yang, Y. S., Wang, D. Y., et al., "Morphological Measurement of Living Cells in Methanol with Digital Holographic Microscopy," Computational and Mathematical Method in Medicine, 2013, 1-7 (2013).

[4] Romuald, J., Yannick, B., and Franck, M., "Skin Parameter Map Retrieval from a Dedicated Multispectral Imaging System Applied to Dermatology/Cosmetology," International Journal of Biomedical Imaging, 2013, 978289 (2013).

[5] B. S. Wang, and A. Sanchez, "All-fiber passive coherent combining of high power lasers," Optical Engineering 50(11), 111606 (2011).

[6] Cai, L. Z, [Optics(3th Edition)], Science Publishing House, Beijing, 149-160 (2007). 